\title{
الواقع الجغرافي والاقتصادي للنفط

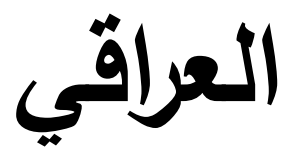

\section{رويتان متناقضتان ـ دراسة في الجغرافية السياسية}

\author{
أ.م.د محمد محي لهيمص
}

جامعة المستنصرية ـ كلية التربية ـ قسم الجغرافية 
مقدمة

يتفق البـاحثون علـى أن الـنظط أصبح أحـد المحساور الرئيسـة للصـراع الاقتصـادي والسياسي في العالم اليوم ، لما يتمتع به من مزايا هامة وعديدة ، فهو سلعة إستراتيجية لها أهميتها في وقت السلم والحرب على السواء . وكان للعراق حصة كبيرة من هذه الثروة وهناك من الدلائل ما يشير إلى ذلك ، والتي تمثل مؤثراً أساسيا لتمويل عملية التنمية وارتفاع دخل الفرد العراقي وانخفاض مستوى الفقر أو وضع نهاية له ، فهي حقا هبة من هبات الطبيعة للعراق ، وهو مـا يتعين على السياسـات أن تسعى إلية في رفاه السكان وزيادة الأصول المالية الأجنبية . هذا ما يؤمل تفسيره ويفترض إحصائيا بالعائدات ووفورات الإنتاج في المجال البحثي ، وخاصة أن للعرلق تضمينات أخرى في تقريز الثروة . وتصـح هذه الحسال أن أديـرت على النحو المناسـب بقصد زيـادة المنـافع الاقتصـادية واستمرار الحكومات على التفكير السليم في أدارة الدولة . ولكن عدلت هذه الحسابات في ضوء مـا خلقته الحرب العراقية الإيرانيـة ، وأحداث أب ـ99 99 وعملية ما سمي بعاصفة الصحراء في 9 / / كانون الثاني / 199 / ، ومـا تبعها من عقويات اقتصادية ، استمرت إلى عام ب . . م والتطورات التي حدثت باحتلاله من قبل الولايات المتحدة ، والمشكلات التي حدثت بعد ذلك . هذا قد لا يكون غريباً إذا ما نظرنا إلى تاريخ العراق الحافل بـالغزوات بسبب خيراتـه الكثيرة والمتنوعة وهناك الكثير من الآراء والاجتهادات للربط بين الاحتلال الحالي والنفط .

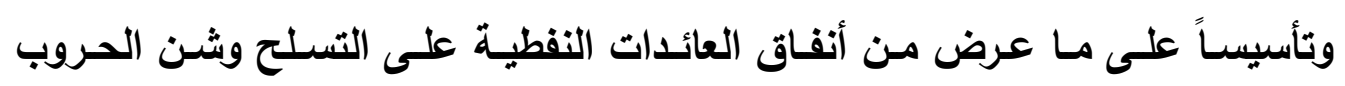
وسلبية الاحتلال الأمريكي ، توقةت عملية التنميـة الاقتصـادية ، عـلاوة على خسـائر ماليـة وتراكم الديون الخارجية ، جعل الأوضـاع الاقتصـادية وغيرهـا تزداد تدهوراً يومـاً إثر أخر ، ويوحي هذا باستهلاك المورد القابل للنفاذ لغير العراقيين ، وهو هدف هذا البحث الذي أستثد على المـنهج التحليلي بالجغرافيـة السياسية ، وافتراضـاً ، على أن جميع ريـوع المـورد يـتم استهلاكها بعد تقدير مخزونها ، شاملة تغيرات عدة في البلد وهي مشكلة البحث التي تمثل وجهة نظر الباحث للأحداث الملموسة وغير الملموسة في العراق . 
ولمعرفة هذه المتغيرات من الأحداث أقتضى مناقثة ما يأتي :-

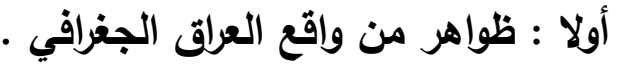

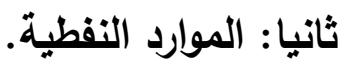

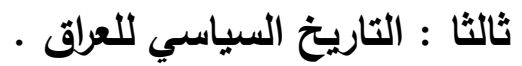

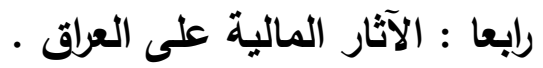

خامسا: تقرير دالة الإحداث: نظرة شاملة.

وخاتمة لهذه الحقائق وما يخالفها وتطلعات المستقبل.

\section{أولاًا : ظواهر من واقع العراق الجغرافي :}

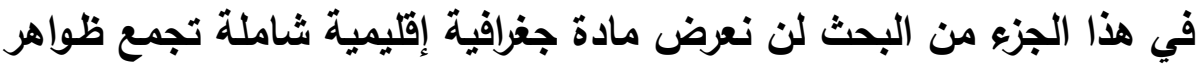

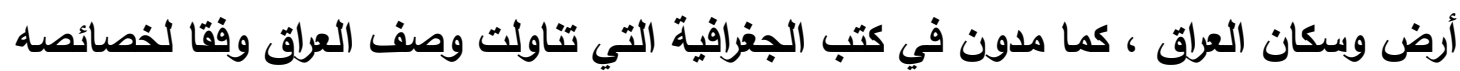

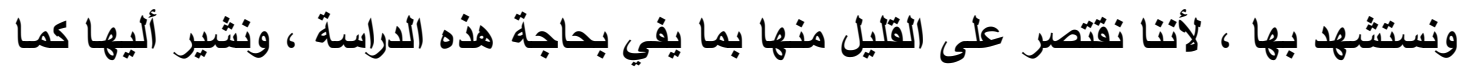

يأتي :

هنالك شروح وتعاريف تكشف عن معنى أسم العرلق في كلام العرب ، مثل البكري

والمسعودي والحموي وياقر وغيرهم وفي مختلف الأزمنة التي ورد الثرح فيها ، وهذه على

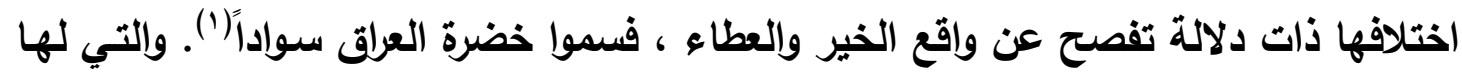

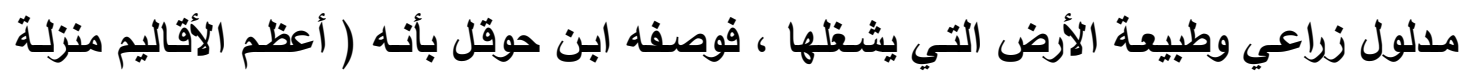

وأجلها صفة وأغزرها جباية وأكثرها دخلاً . . . )(†').

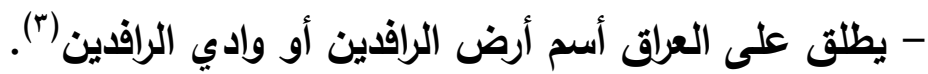

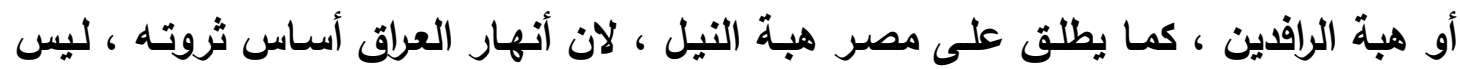

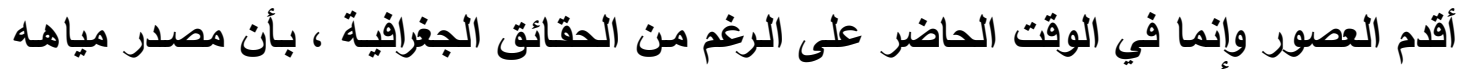

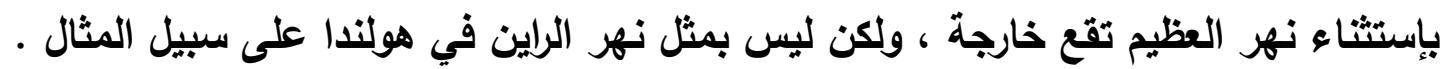

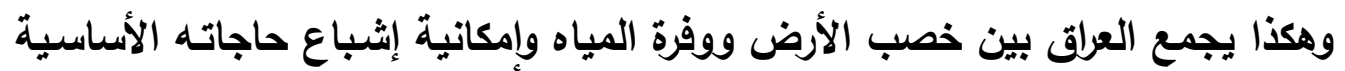
والثانوية منهما بعد قدرة القيادة فيه على التفكير السليم ويراعتها في رسم الخطط على أسس ولى

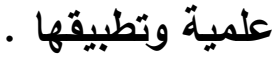

(1) طه باقر ، مقدمة في تأريخ الحضار ات القديمة ، الجزء الاول ، بغداد ، دار الثؤون الثقافية العامة ،

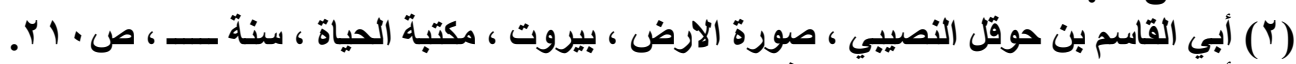

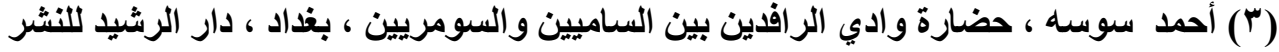


- تثير دراسـة متاحة إلى أن احتياطي الثروة المعدنية في العرلق جدول ( ) ) ، الذي يؤكد

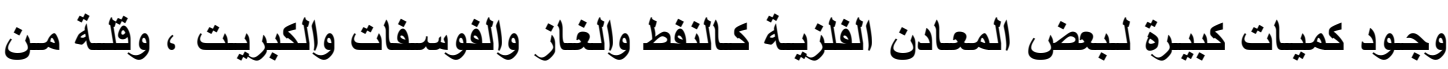

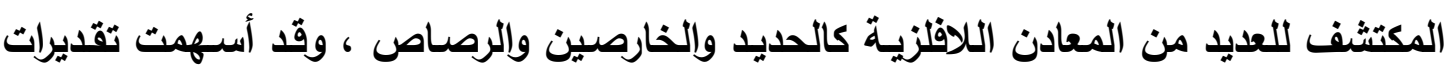

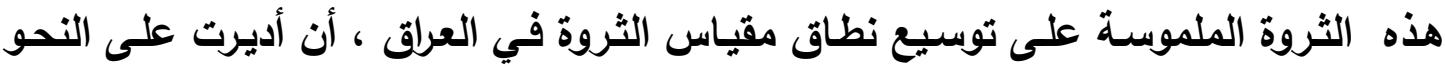

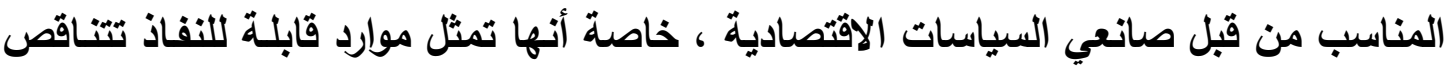
بزيادة الإتتاج ، بدلالة ما يحدث اليوم وكما ذكرتها الأخبار . 


\begin{tabular}{|c|c|c|}
\hline الاحتياطي & المادة & $ت$ \\
\hline . . . مليار برميل & النفط & -1 \\
\hline . . . اس مليار متز مكب(') & الغاز & $-r$ \\
\hline 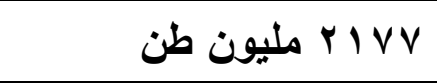 & حجر الكلس & $-r$ \\
\hline 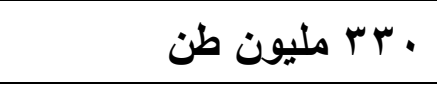 & الدولومايت & $-\varepsilon$ \\
\hline 1 ؛ ؛ مليون طن & أطيان السمنت & -0 \\
\hline צ^r مليون متر مكعب & أطيان الطابوق & -7 \\
\hline • rا مليون طن & الجبس & $-v$ \\
\hline 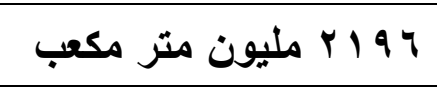 & الحصى والرمل & $-\Lambda$ \\
\hline 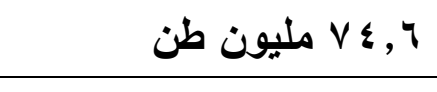 & رمال المرو ( الزجاج ) & -9 \\
\hline 1ه مليون طن & الكاؤولين & -1 \\
\hline rro مليون طن & الفوسفات & -11 \\
\hline با 11 مليون طن & الكبريت & $-1 r$ \\
\hline ه7, • مليون طن & النيتونايت & $-1 \mu$ \\
\hline 7 ؛ مليون طن & الملح ( عدا مياه البحر ) & $-1 \leqslant$ \\
\hline آ مليون طن & خام الحديد & -10 \\
\hline r r, مليون طن (ץ) & الخارصين والرصاص ( فلزات نقية ) & -17 \\
\hline
\end{tabular}

المصدر

OPEC Annual statistical Bulletin , 1992 , The Secretariat ( $)$ Organization of The Petroleum Exporting Countries , Vienna, 1993, pp.36-38.

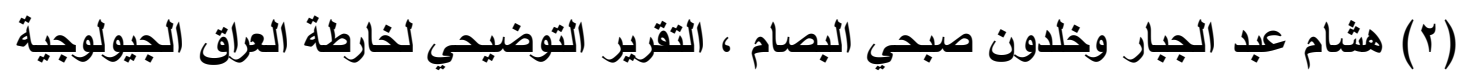

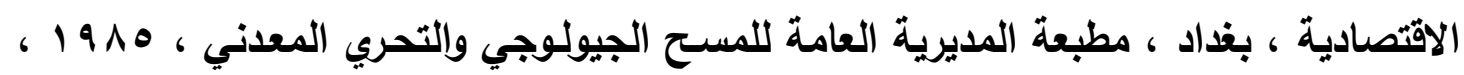


(وهناك تعديل كبير في الاحتياجات الخاصة بالمعادن اعلاه ترفع ارقامها عالياً ولاسيما النفط

- يمكن القول بأن العرلق يتميز بفترة نمو طويلة تتراوح ما بين عشرة أشهر في صلاح الدين

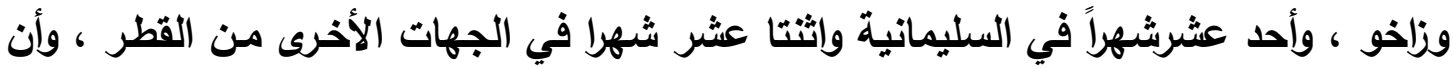

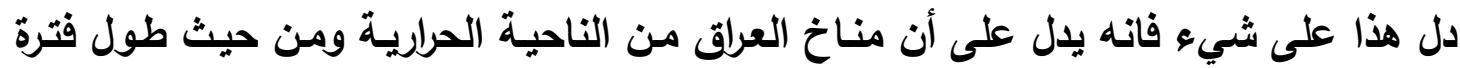
النمو ملائما للإنتاج الزراعي ، سواء كان لإنتاج المحاصيل الثتتوية ، أم الصيفية التي يمكن

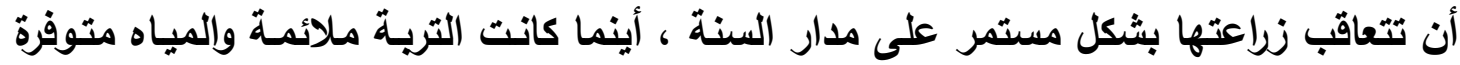

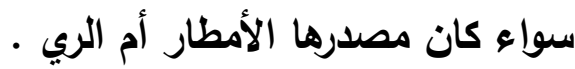

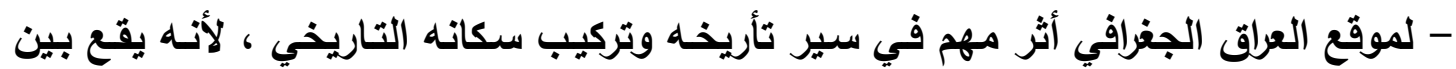
منطقتين ، الملحوظ عليهما التباين بتضـاريس سطح الأرض والتثـابه مـن حيث قلـة الكـلأ

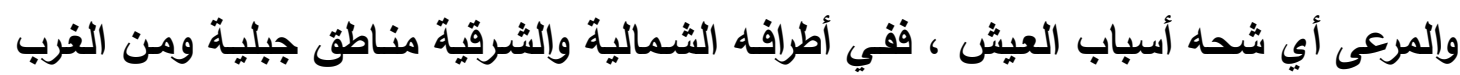
والجنوب الغربي مناطق صحراوية مقفلة ، مما جعل العرلق محط أنظار أقوامها وهجراتهم إليه

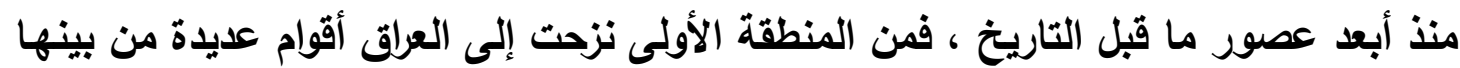

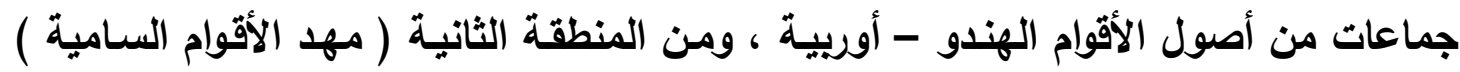

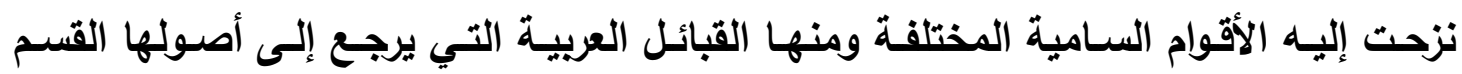

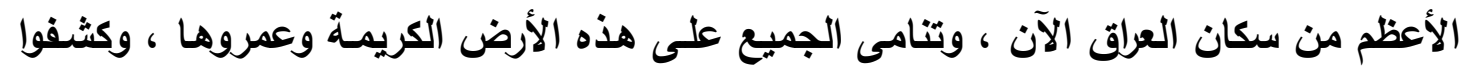
عن فاعليتهم على الصعيدين العربي والإسلامي (1). وتكثف متابعة الموضسوع في كتب التاريخ والجغرافيـة والسياسـة في تطور ظواهر الهر الحياة العامة التي منها جوانب توزيع السكان على أسساس الخصائص الدينية والقومية التي فئي

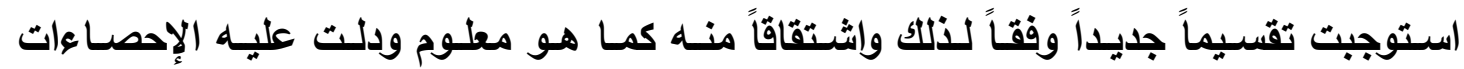

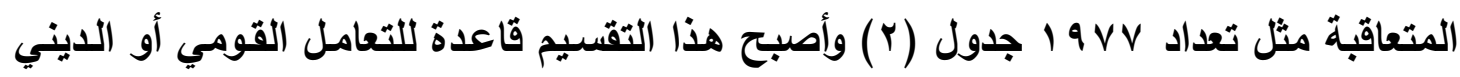
أو السياسي كما هو معروف اليوم في العرلق وفق متطلبات قوات الاحتلال ومن سـار معهم ، ولن نعرض لله هنا . ومهمـا يكن مسن أمر تبرز حقائق مهمـة من سكان العرلق معروفـة بنتائجها، وتثـمل نمو

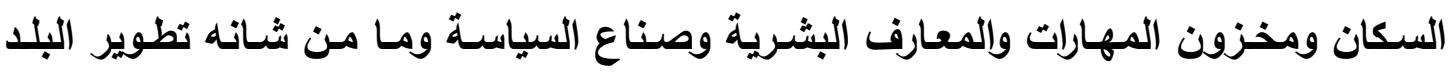

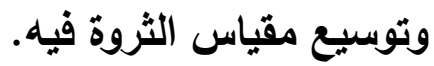




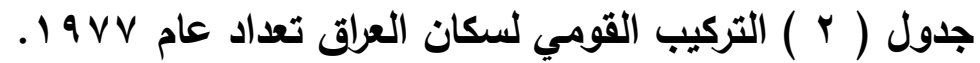

\begin{tabular}{|c|c|c|c|}
\hline النسبة \% & العدد & القوميات & ت \\
\hline$\wedge 1, \wedge$ & $q \vee \cdot r \wedge \leq q$ & العربية & -1 \\
\hline 10,9 & $|\wedge q| \wedge \wedge \vee$ & الكردية & $-Y$ \\
\hline$\cdot, 1$ & 11010 & الفيلية & $-r$ \\
\hline 1,10 & I HVY 19 & التركمانية & $-\varepsilon$ \\
\hline •,or & $\neg Y \wedge \mid q$ & السريانية & -0 \\
\hline & & الأثورية & -7 \\
\hline$\cdot, 1 r$ & I HVoo & الأرمنية & $-V$ \\
\hline$\cdot, 1$ & $1179 \%$ & اخرى & $-\Lambda$ \\
\hline$\bullet, \mu$ & $r \cdot \Lambda \Lambda \varepsilon$ & غير مبين & -9 \\
\hline $1 \ldots$ & I1АятяY. & المجموع & -1 \\
\hline
\end{tabular}

المصدر: نتائج التعداد العام للسكان في العراق عام I VVV.

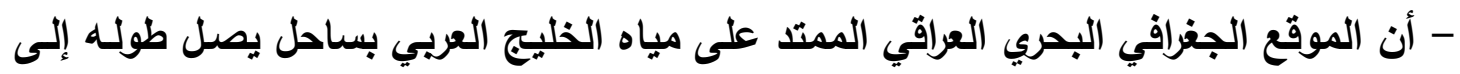

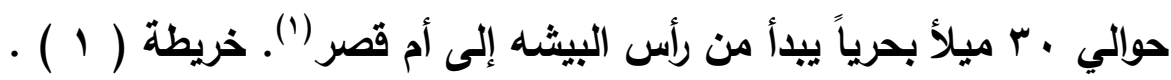

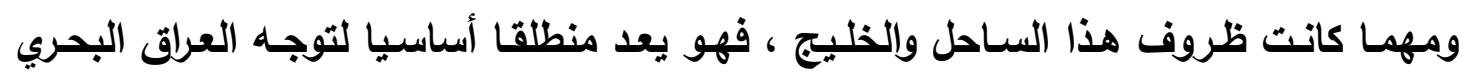

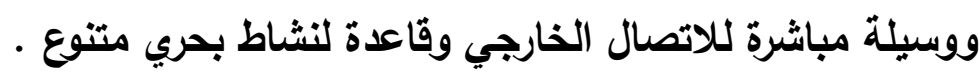

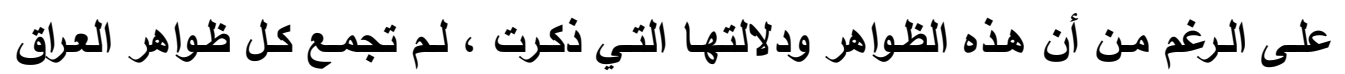
الجغرافية لأنها كثيرة ، لكنها أبرزت جانبا وفق منهج البحث في جوهره يرسم شخصية العرلق

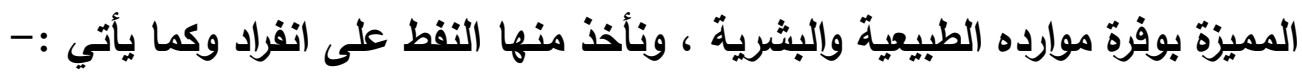




\section{خريطة (1) : ساحل العراق على الخليج العربي.}

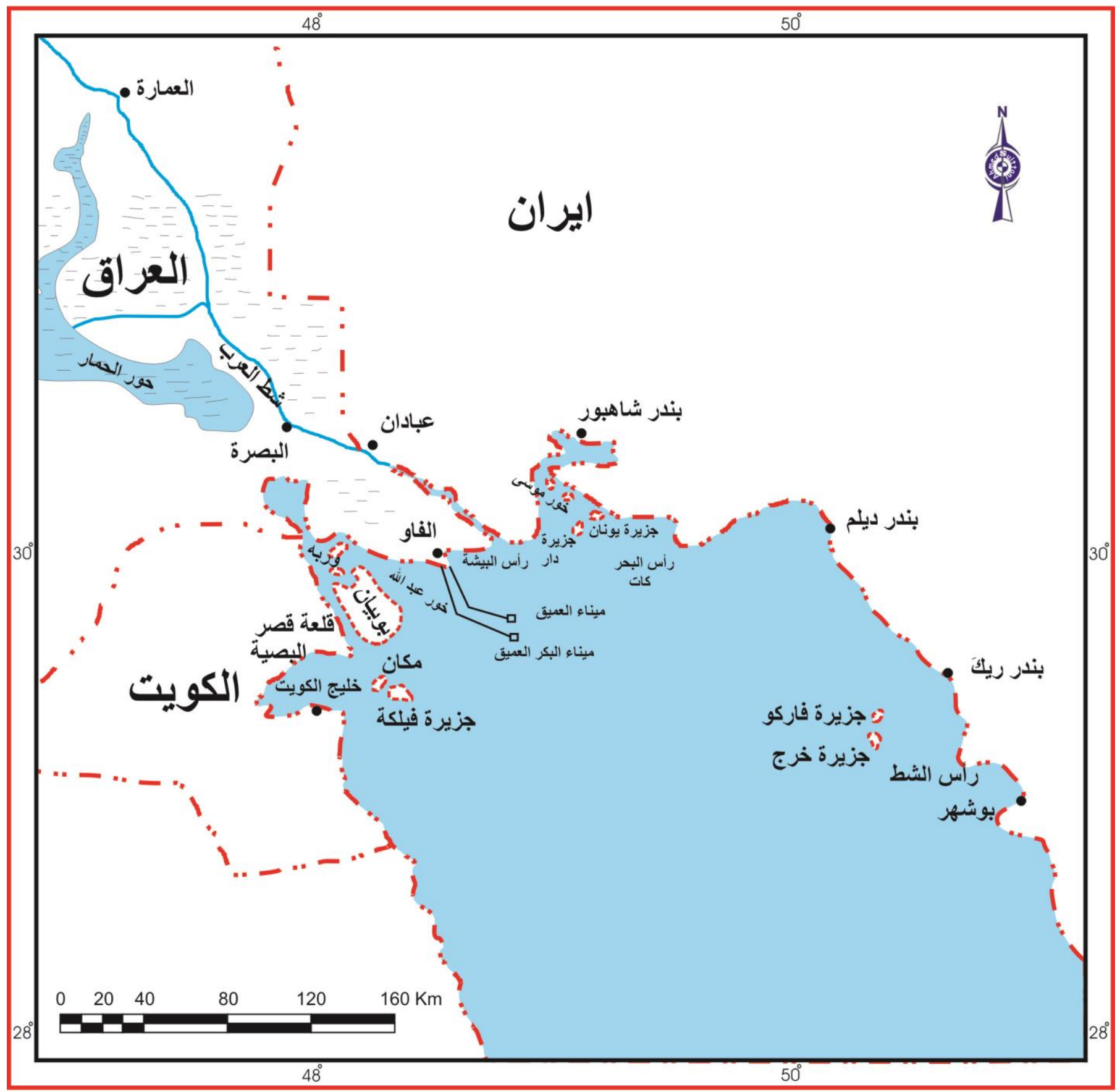

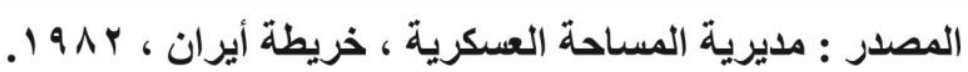


ثانيا - الموارد النفطية

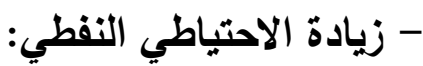

قال رسول الله ( صلى الله علية وسلم ) ( (ابتغوا الرزق في خبايا الأرض ) (') وكان

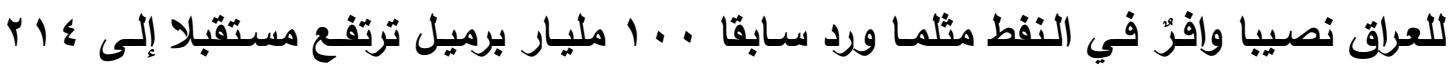

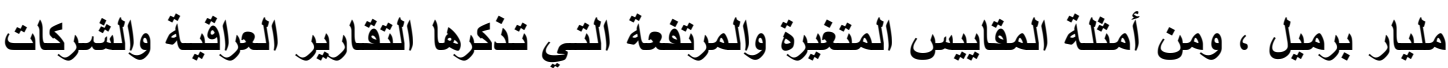

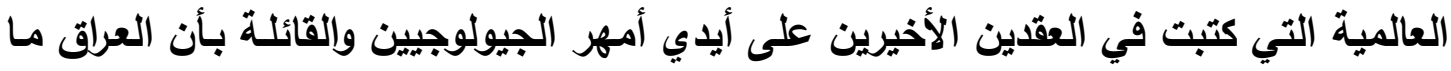
زال ينتج نفطه من عصرين جيولوجيين فقط وهما الثلاثي والطباشيري بينما هناك ترسبات التهين نفطية هائلة لا يمكن تصورها تعود إلى العصر الجوراسي الذي هو العصر الرئيسي المنتج

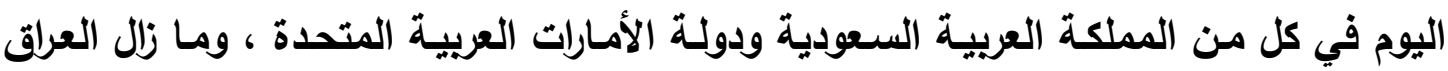

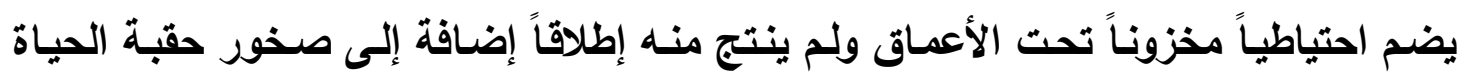
القديمة ، وهذه تحتوي على نفوط كل من المملكة العربية السعودية وعمان التي لم ينتج منها

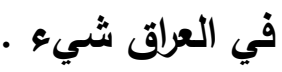
وعليهه ، فأن التقديرات لإستراتيجية احتياطيات العرلق ستتفوق في السنوات القادمة

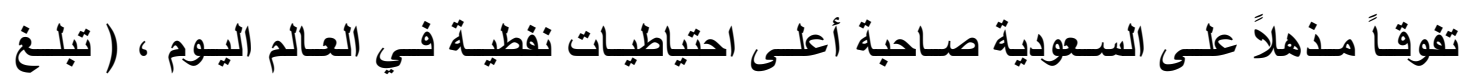

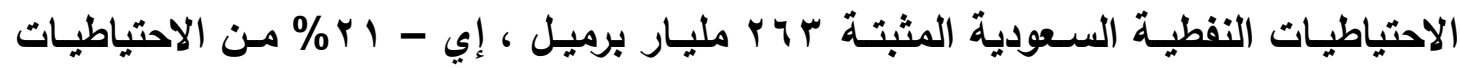

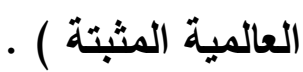
وتثير التقديرات أيضاً أنه ستزيد نسبة احتياطي نفط العراق في العالم الثلاثين عاما

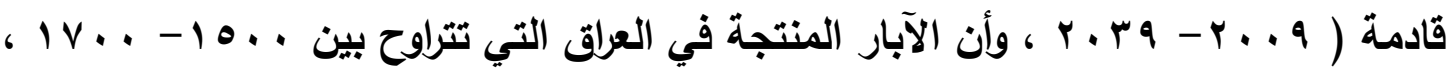
بئر من المتوقع أن تصل باستكمال التنقيب إلى مالا يقل عن . 1 ألف بئر(؟). وقد صاحب هذا الاحتياطي استخدام النفط بالعديد

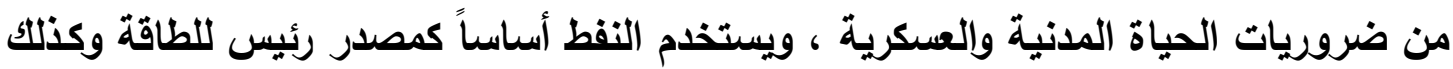

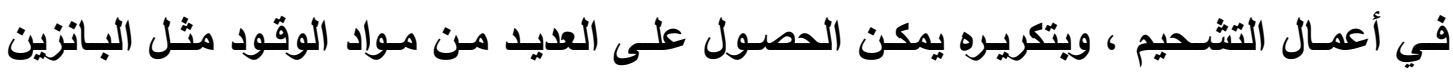

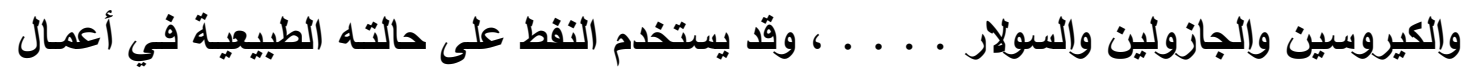

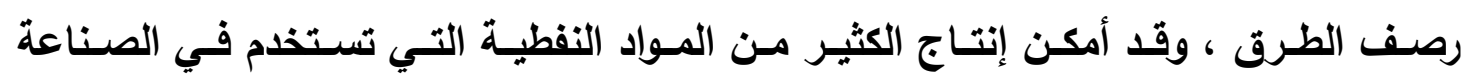

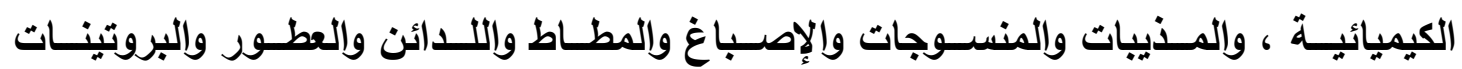
والمتفجرات وغيرها من المواد الحديثة . 
ويتصل ذلك بزيادة عدد سكان العالم وما يصاحب ذلك من حاجاتهم إلى مصدر للطاقة لا يمكن توفيره بصورة رئيسة الأ عن طريق البترول على الرغم من محاولات استخدام الطاقة لمانة

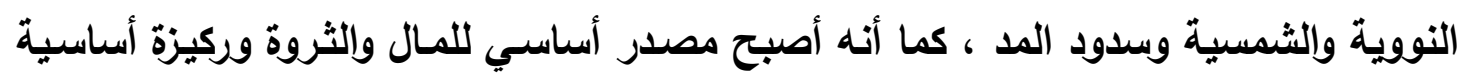

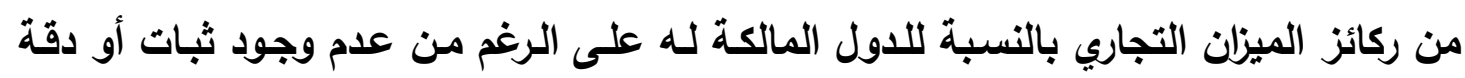

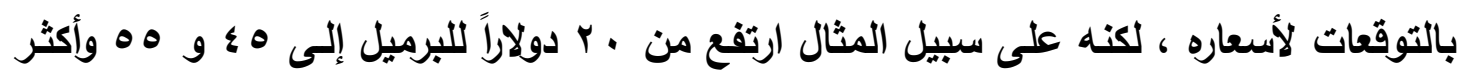

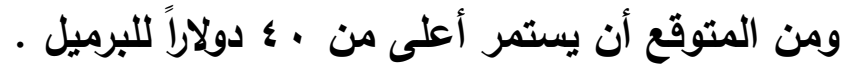

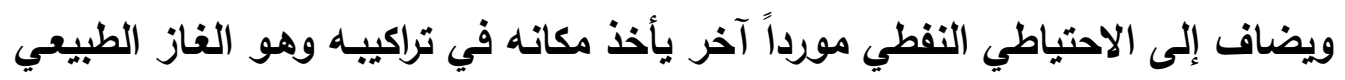

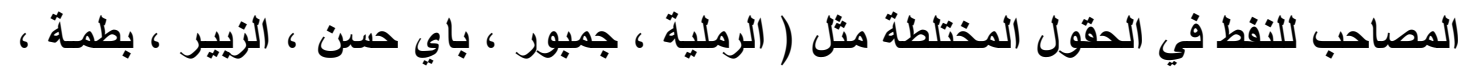

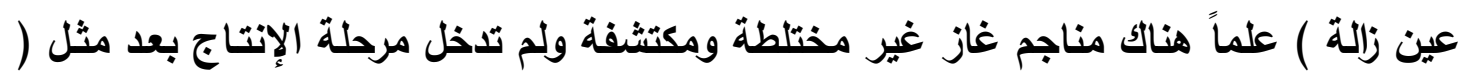

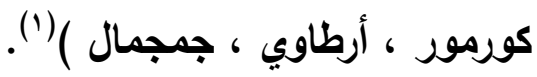

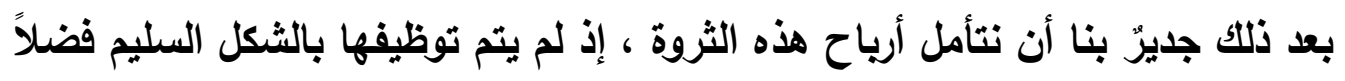

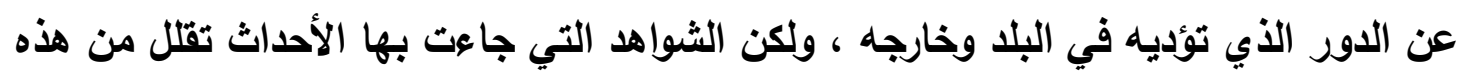

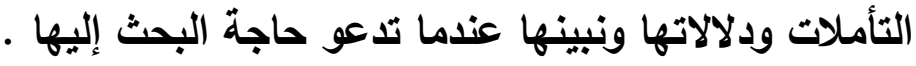

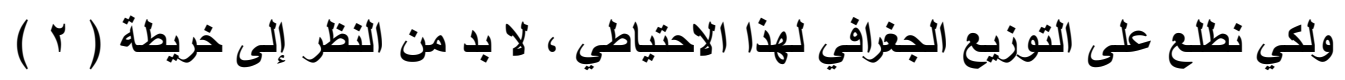

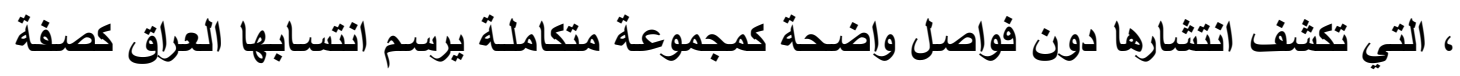

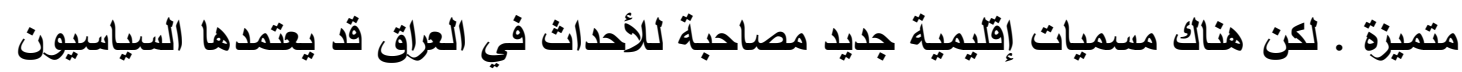

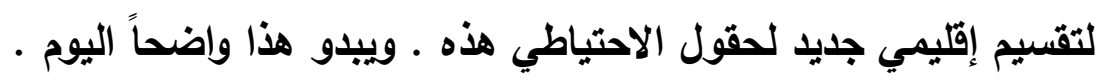

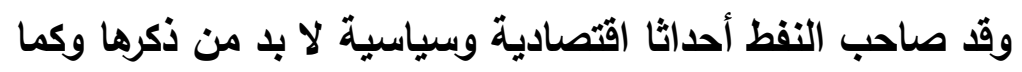




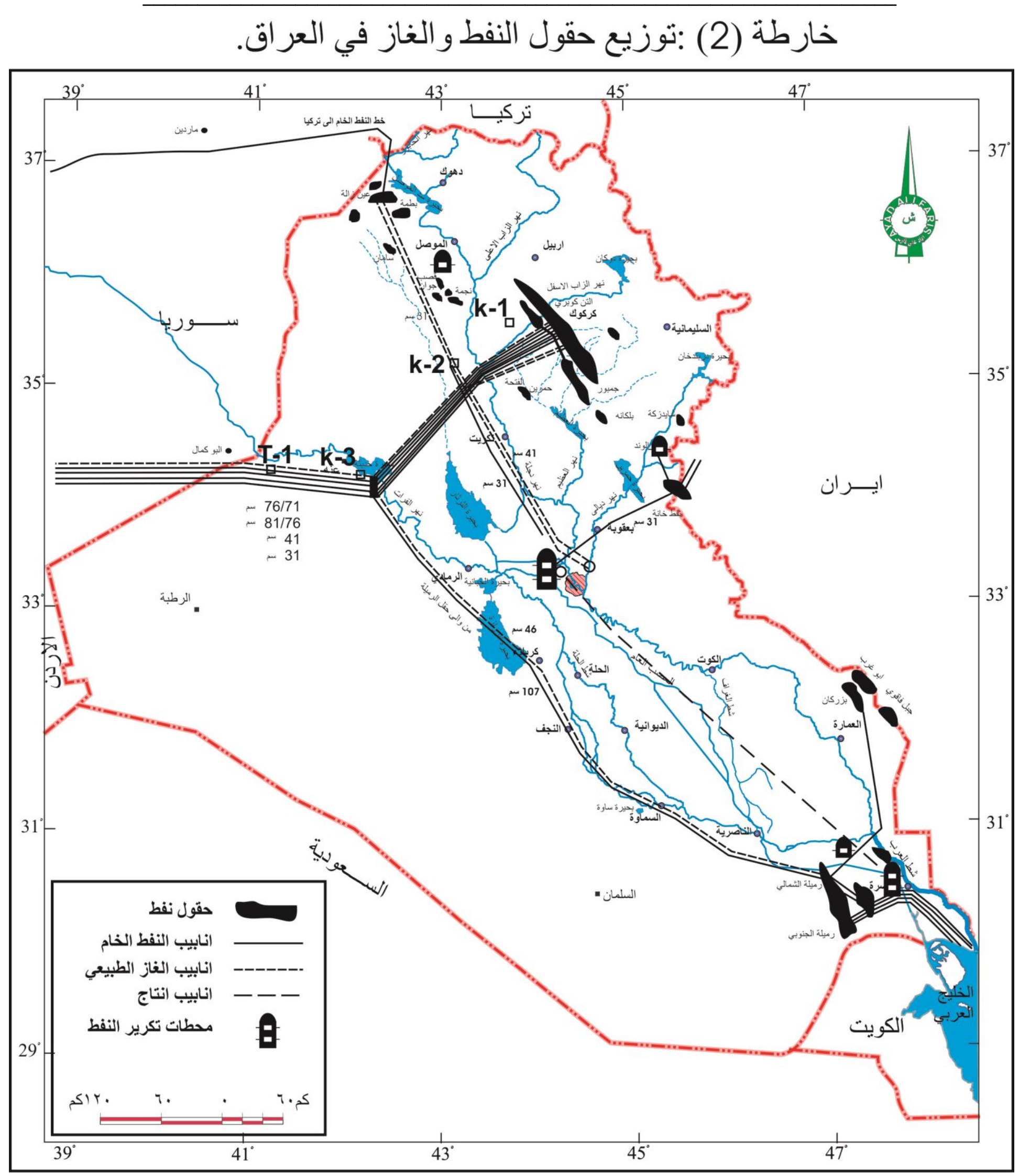

Opec Annual Statistical Bulletin, 1992, P.129 : المصدر 


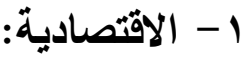

العرق أقدم أقطار الوطن العربي بعد مصر أنتاجاً للبترول إذ بدأ أنتاجه لأول مرة في

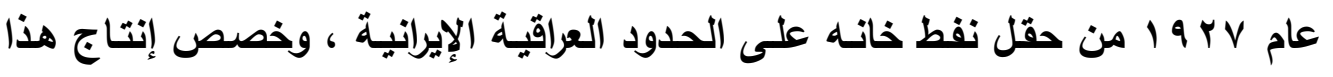

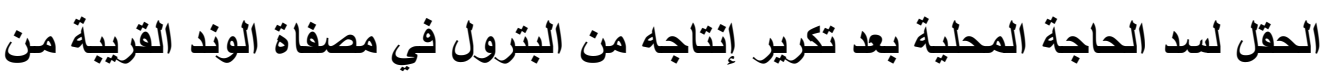
الحقل المذكور ، وفي عام \& ب 19 بدأ الإنتاج من حقل كركوك (1).

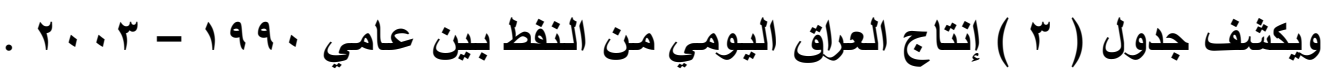

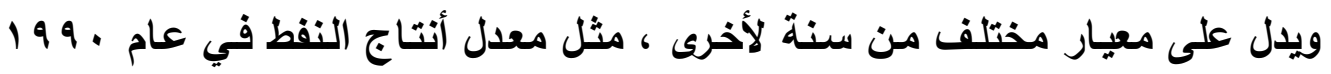

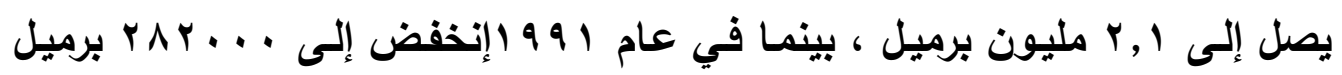

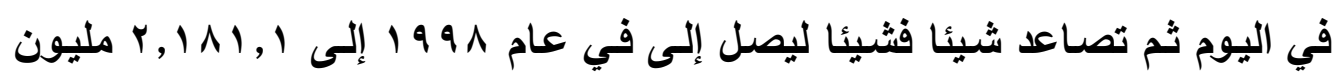

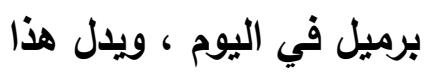

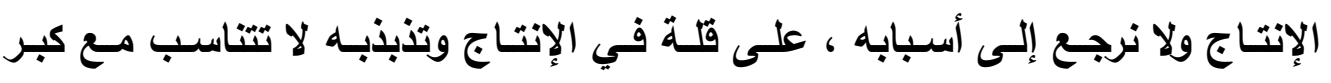

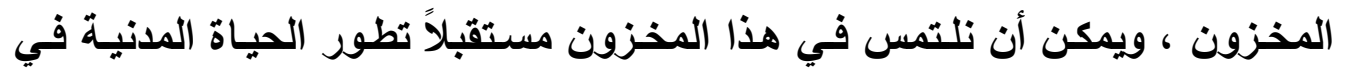

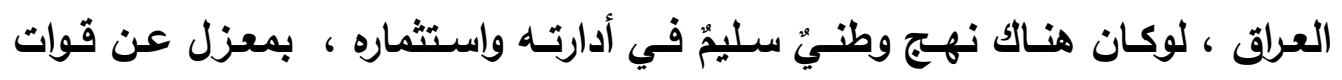

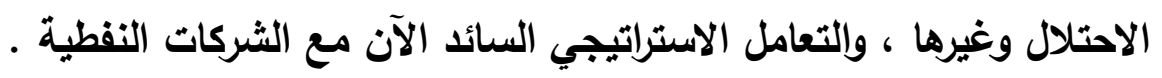


جدول ( r ) إنتاج النفط العراقي منذ عام ـ 199 ـ .

\begin{tabular}{|c|c|c|}
\hline إنتاج النفط ( إلف برميل يومياً ) & 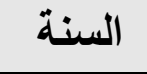 & $ت$ \\
\hline$r, \| r, V$ & 199. & -1 \\
\hline 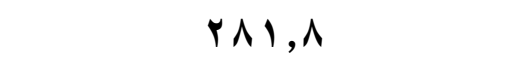 & 1991 & $-r$ \\
\hline or, r & 1994 & $-r$ \\
\hline 909,0 & 1994 & $-\varepsilon$ \\
\hline$\vee \leqslant \Lambda, \vee$ & $199 \leq$ & -0 \\
\hline VPq, q & 1990 & -9 \\
\hline$V \varepsilon,, \varepsilon$ & 1997 & $-v$ \\
\hline 1,rAr,q & $199 V$ & $-\wedge$ \\
\hline$r, \mid \wedge 1,1$ & 1991 & -9 \\
\hline$r, \vee \backslash q, \Lambda$ & 1999 & -1 \\
\hline$r, \wedge 1 \cdot, r$ & $r \ldots$ & -11 \\
\hline$r, \Delta q r, V$ & $r \ldots r$ & $-1 Y$ \\
\hline$r, 1 Y q, 0$ & $r \ldots r$ & $-1 r$ \\
\hline $1, r r \wedge, \cdot$ & $r \ldots r$ & $-1 \leqslant$ \\
\hline
\end{tabular}

المصدر : علي حسين ، مستقبل تمويل الصناعة النفطية العراقية ، أبو ظبي ، مركز

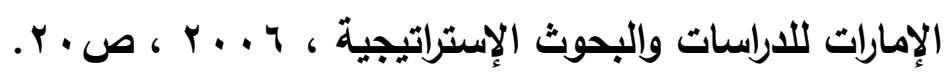


r

يمكن أن نحدد خطوات للحكومات العراقية ، لوضع اليا على الثركات التفطية العاملـة

في العراق وصولاً إلى التأميم وسيطرة الدولة ثم محاولات تقليص هذه السيطرة ، كما يأتي :العراق أول قطر عربـي أتخذ الإجراءات الكفيلـة بتحريـر أرضـه من سبطرة الشـركات

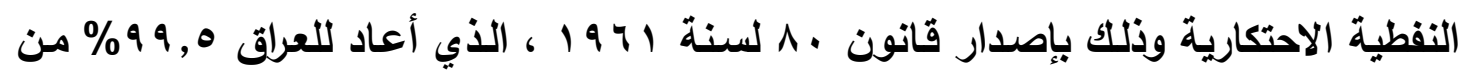
الأراضي المشمولة بامتيازات شركات النفط الأجنبية العاملة في العرلق وترك للشركات المذكورة I TrV

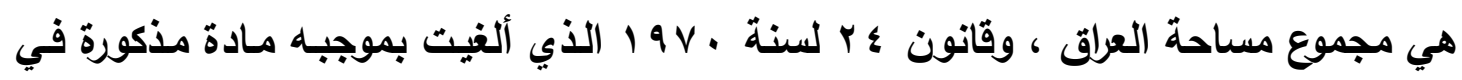

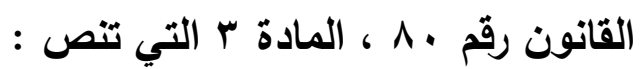
(( لحكومة الجمهورية العراقية إذا ارتأت تخصيص أراضي أخرى لتكون احتياطا للشركات على أن لا تزيد على مساحة المنطقة المحدودة لكل شركة )) ويذلك أغلق الباب نهائيا لأي تفكير

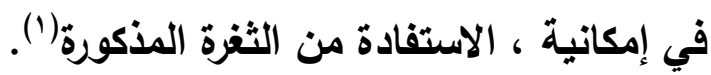
وكان العراق أيضـاً أول قطر عربي حرر نفسـه من التبعية لشركات النفط الاحتكاريـة بتأميم نفطه وذلك بعدد من القوانين اعتباراً من اليوم الأول من حزيران عام 19 Y وحتى عام ه 9 V ، ويذلك سيطرت الحكومة العراقية على كل أنتاج القطر من النفط . ويحمل تتابع التاريخ حركة لها شأن كبير في مسار ذلك وأحوال سكان العرلق أيضا

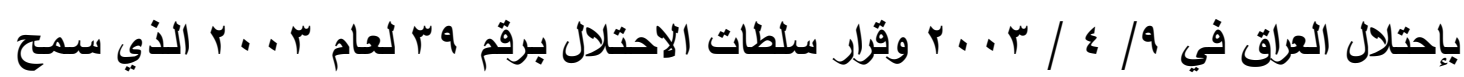
بالامتلاك الأجنبي الكامل في كل الصناعات العراقية باستثناء النفط والموارد الطبيعية الأخرى (المبية

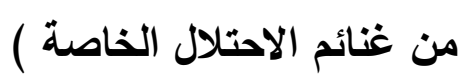
وهناك من يدعو إلى خصخصة النفط العراقي أو بعض الحقول منه وما يتبعه وتقضسي به السياسة في العراق اليوم ، بتخطيط دولي وأوامر الإدارة الأمريكية خاصة . أمّا بالنسبة إلى عمليات نقل وشحن النفط العراقي فله منافذ مختلفة : محطة تحميل البصرة ، ومحطة تحميل خور العمية ،وخط الأنابيب التركي ، والسـوري ، والسـودي ، قـ يضاف أليها مستقبلا الأردن والكويت ، وهذا وفر للعراق مرونـة في توصيل نفطه إلى سواحل ، البحر المتوسط وموانئ الخليج العربي حسب الظروف السياسية والاقتصادية مع هذه الدول أو المنطقة . 
ولا بـ من الإثـارة إلى مشروع تصدير الغـاز الطبيعي إلى تركيا التي عرضت على العرلق عام 197 ا هذا المشروع ، تصدير الغاز من جنوب العرلق إلى تركيا ، وقد وافق العراق على ذلك ، ووقع الاتفاق في عام 197 19 ، ، حيث تعهد العرلق بتجهيز تركيا بكمية من الغاز

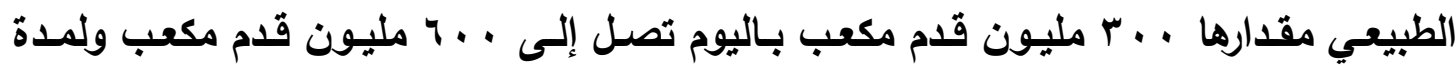

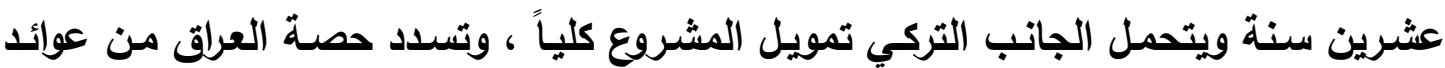

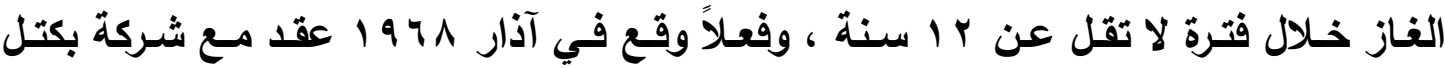

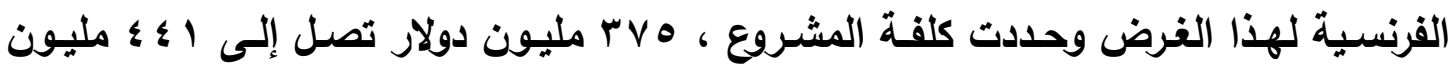

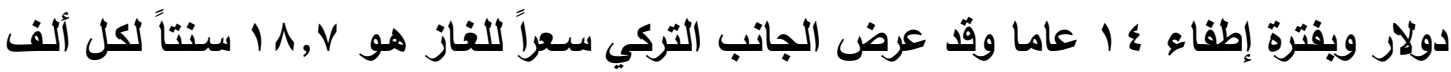

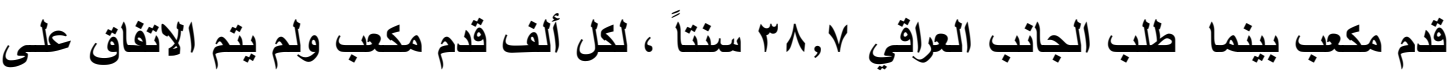
ذللك ، واقترح العرلق استبدال هذا المشروع بمشروع اصغر حجما يقتصر على تصدير الغاز

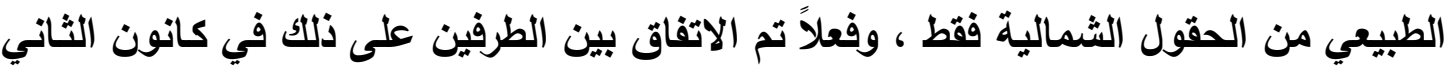

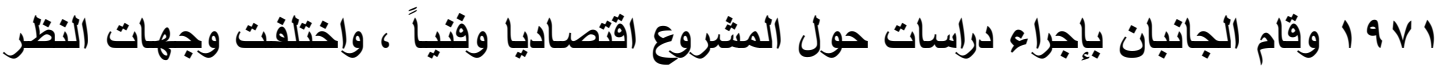

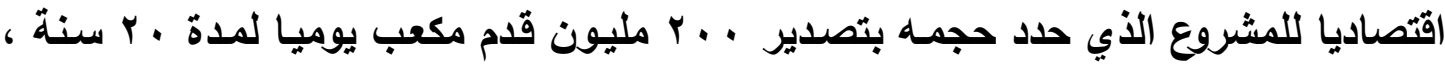

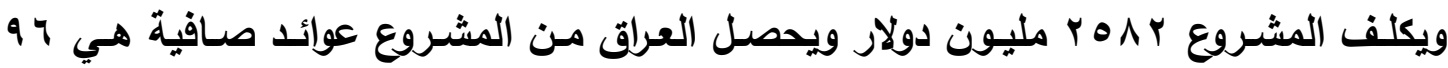

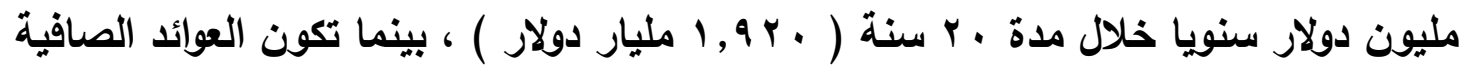

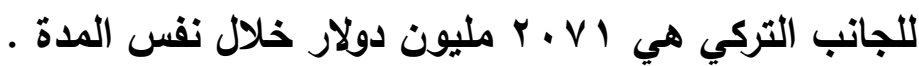

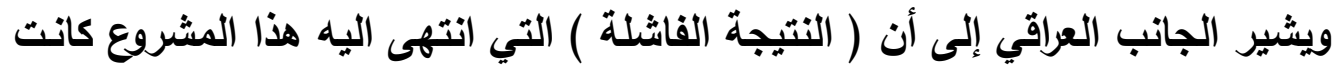

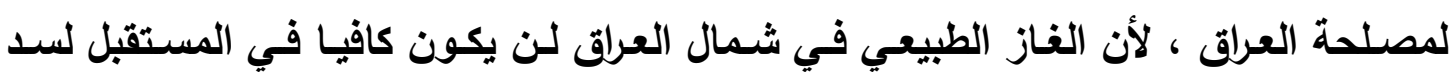

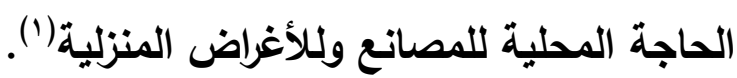

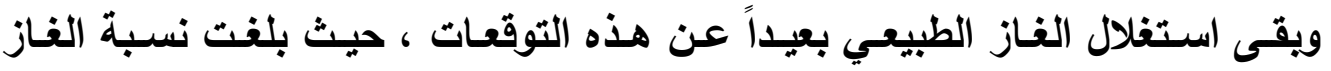

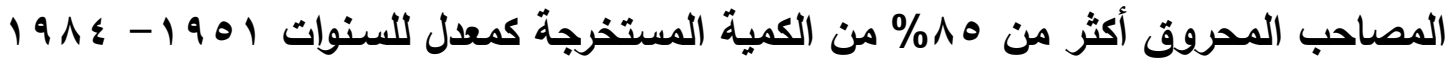

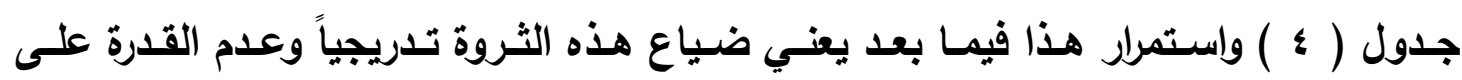

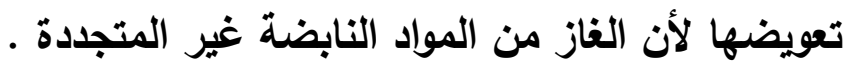


جدول ( ؛ ) قيمة الغاز المحروق في العراق للسنوات 1901 - ؛ 191 ـ

\begin{tabular}{|c|c|c|c|c|}
\hline القيمة مليون دولار & السعر لكل إلف قدم & بليون قدم مكبة المحروقة & السنة & ت \\
\hline $91 \mathrm{r}$ & • r سنت & $r \cdot \varepsilon$. & $19 v r-1901$ & -1 \\
\hline 9ท人 & r ب دولار & & $191 \leq-19 V \leq$ & $-r$ \\
\hline 1.791 & 一 & trat & المجموع & $-r$ \\
\hline
\end{tabular}

المصدر: وزارة التخطيط ، الجهاز المركزي للاحصـاء ، مديريـة الحاسبات القومية دراسـة رقم

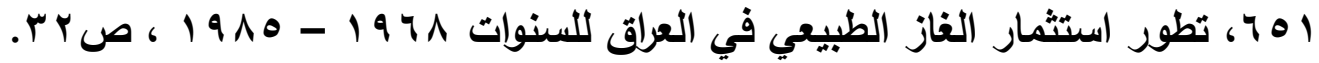

$$
\text { r- أهمية النفط في الاقتصاد العراقي : }
$$

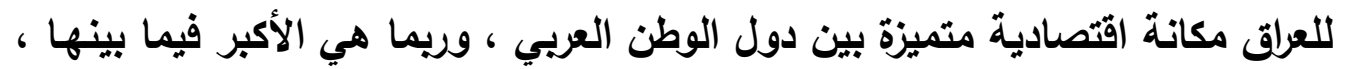

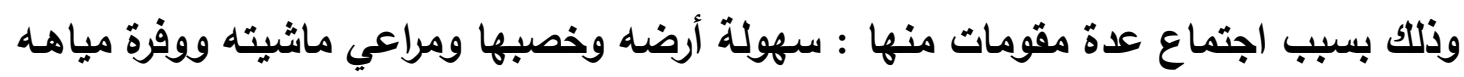

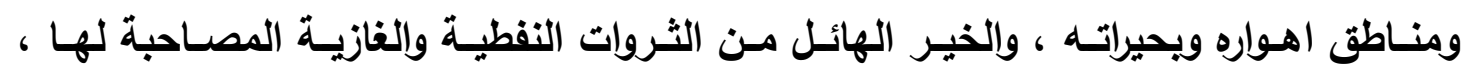

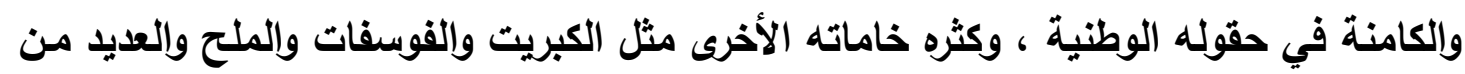
المعادن الفلزية مثل خامات الحديد والرصاص والنيكل وغيرها ، والإمكانيات السياحية الدينية والتاريخية ، وغيرها .

والعرلق قطر فتي بفتوة وشباب سكانه الذين يكونون قاعدة واسعة للأيدي العاملة

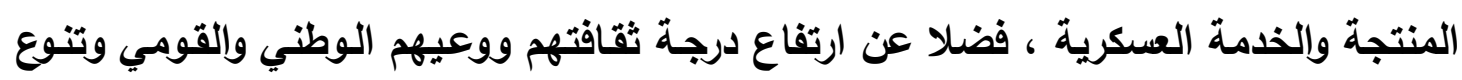
حرفهم وكثيرمن المميزات الآخرى .

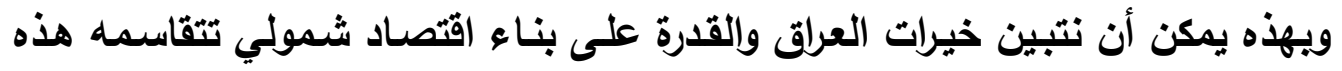

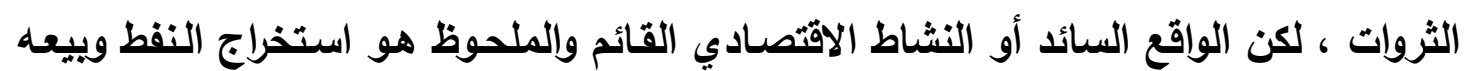

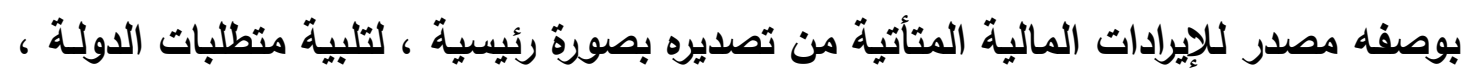

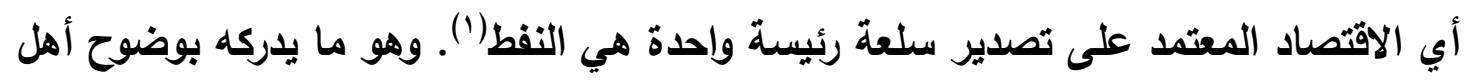


العرلق وغيرهم لأسباب مختلفة ، ومـن بينها حقيقة جوهريـة تتصل بمنهج الدولية وفلسفتها

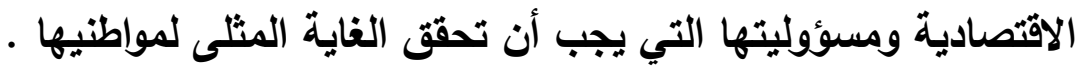

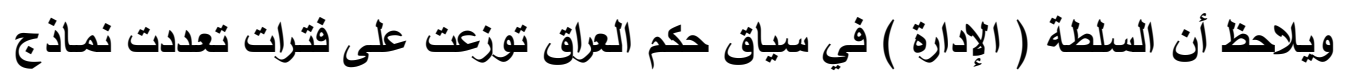
الحكم فيها ، ومن الضروري أن نثير إليها كما يأتي: الإلئ ثالثاً : التاريخ السياسي للعراق ومن الفروي ان من المكن تقسيم التاريخ السياسي للعرلق على ثـلاث مدد رئيسـة هي العهد الملكي

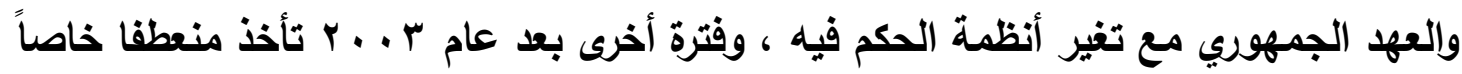

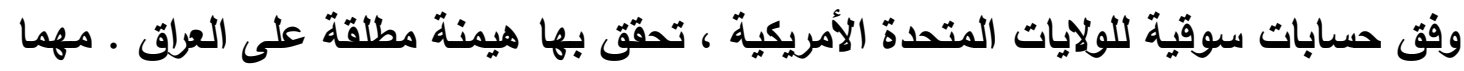

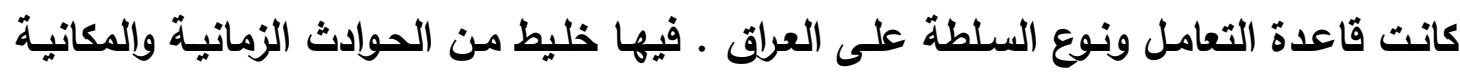

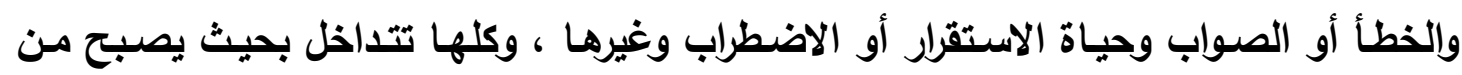

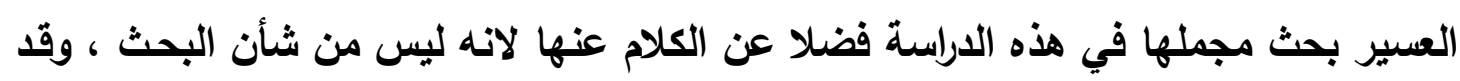
التفت إليها العديد من الباحثين وتركت سمات واضحة على العرلق بنوعية السياسة السائدة في

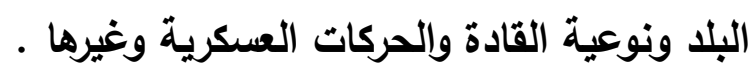

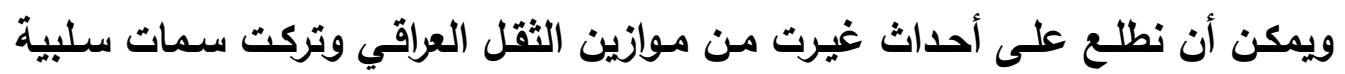
واضحة عليه في حاضره ومستقبله نثير إلى ما سمي بالقادسية ( الحرب العراقية - الإيرانية

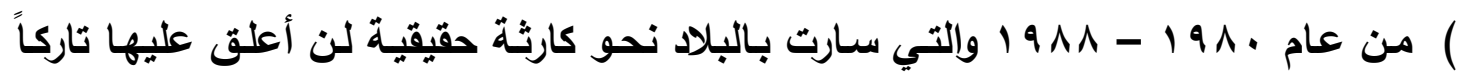

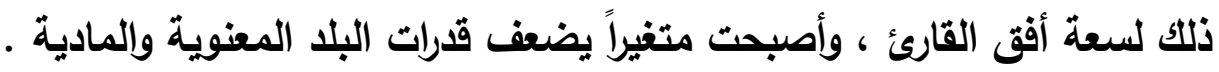

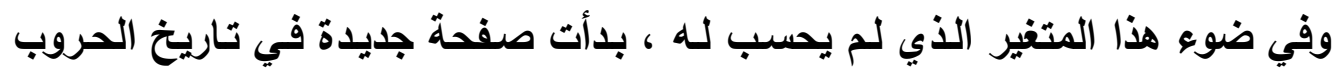
العراقية والتي تتصل بأحداث أب عام ، 99 أب وحتى الاحتلال الأمريكي البريطاني للعراق عام $. r . . r$

جاء الفعل العكري ضد العراق نتيجة دخولهـ الكويت ، والذي رسمته أطراف دولية

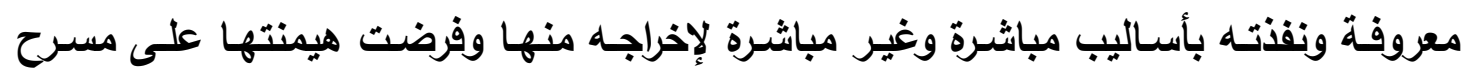

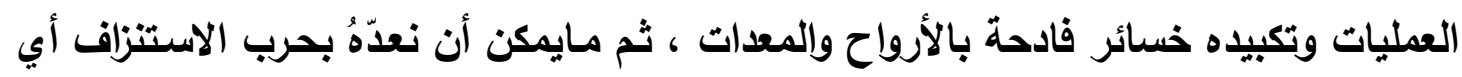

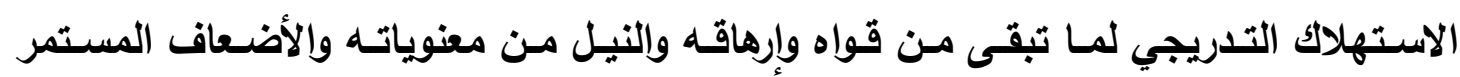
لمقدرته على الرد والمقاومة (') ويعد عام r . . ب جاء الاحتلال الأمريكي وإضحاً وشـاملاً ومتجهاً نحو هيمنة كاملة

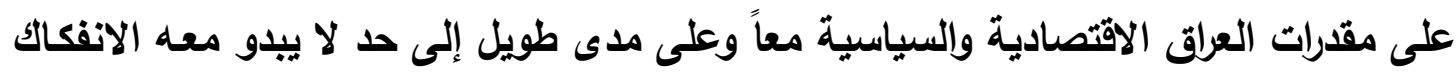
منه سهلاً. 
كل تلكك الأمور وغيرها تل دلالة واضحة وأكيدة على خسائر لا مبرر لها ، قد تكون محسوية أو غير محسوية العواقب ، لا تعير أيسة أهمية لأرواح الناس يضاف ولافئ إليها الأعباء

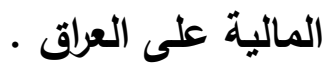

وهكذا كانت لها اكبر الأثر على الاقتصاد العراقي لا بـ من مناقشتها بصورة واضحة وكما يأتي :

رابعاً : الآثار المالية على العرلق سنعرض على سبيل المثال وضع العرلق المالي قبيل حرب عام • 191 ، حيث تراكم

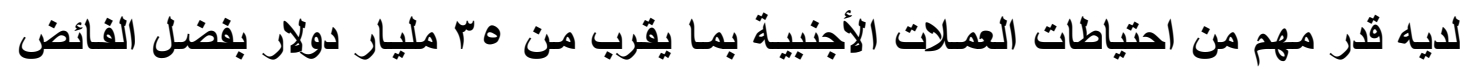

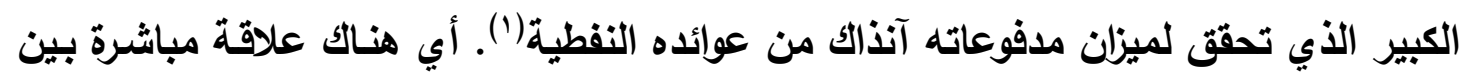

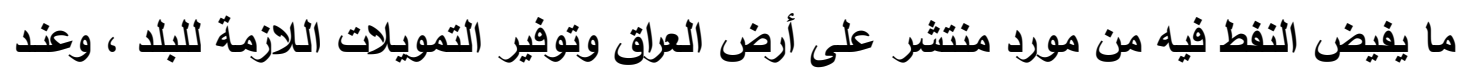

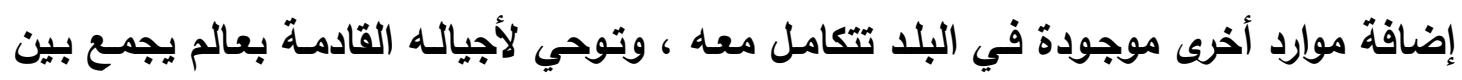
سرمد الماضي وتطلعات المستقبل . وهذا أمرٌ يعد من محاسن البلا ومزاياه التي أظهرت فضله ، ومن خلال الحرب العراقية

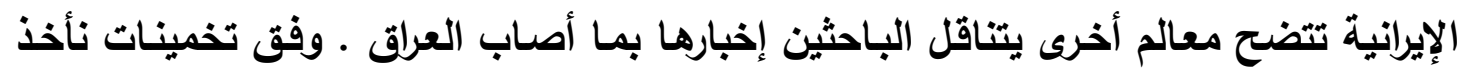
منها : مـن بين الأضـرار التي تكبدها الاقتصـاد العراقي خسـارة مـا يقرب مـن با مليار دولار من

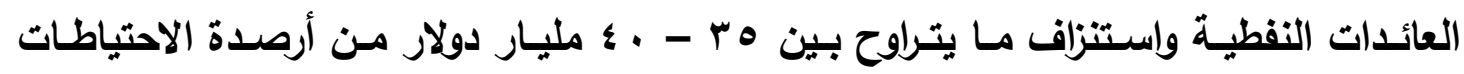

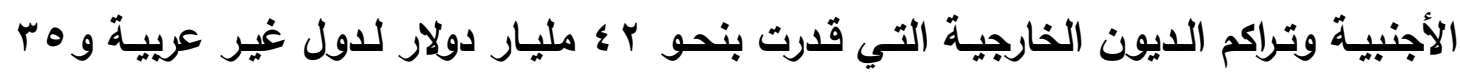

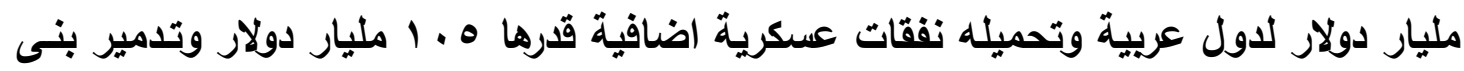

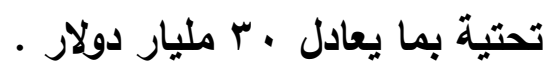
وعلاوة على هذه الخسائر المالية فقد توقفت عملية التنمية الاقتصادية جراء غياب

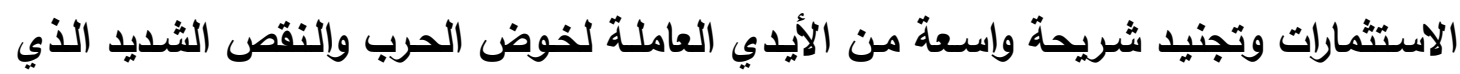

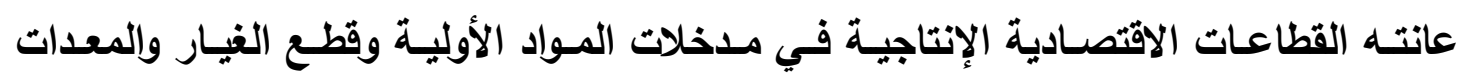

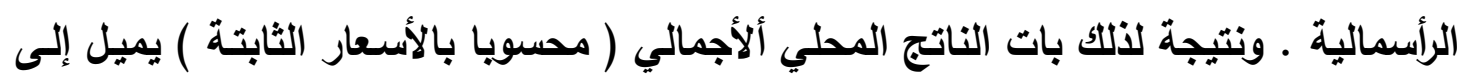

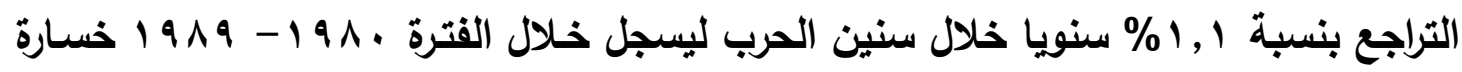


أجمالية قرها ب ؟ ب مليار دولار تقريباً ( بالأسعار الثابتة لعام • 191 ) فضلا عن الخسائر

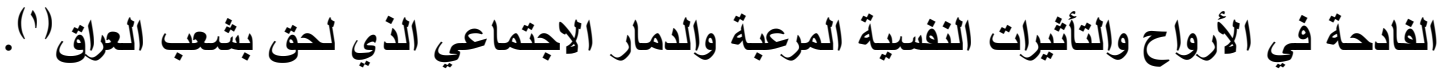

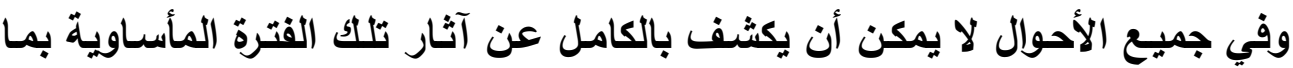

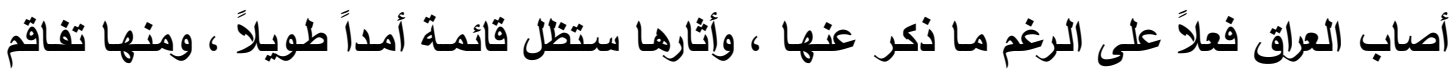

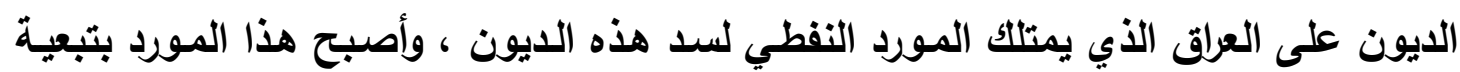
دولية ليسدد مبالغ كبيرة على حساب التنمية والبناء . ولـن نستحسن دخول الجيش العراقي إلـى الكويت ولن نـلـل في تفاصيل دخولـهـ ومسار الأحاثث بعد ذلك لكن نشير ولو عابراً إلى استتتاجات تتعلق بتقديرات تكلفة الاضرار

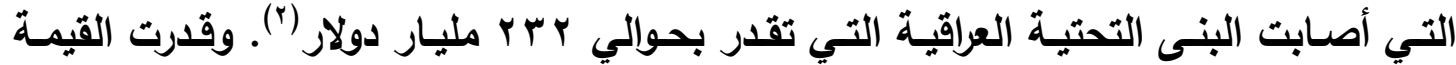

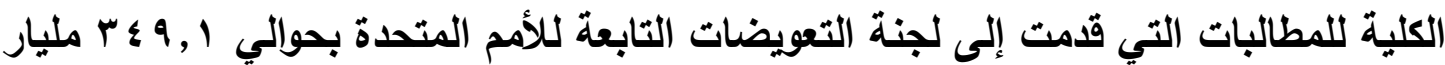
دولار (r). أن هذا العجم المقدر للخسائر النقاية المترتبة على العراق قد يزيد أو يقل ، لكن في المقابل سيكون الدخل النفطي العراقي رهينة لها لسنين قادمـة ممتدة في مستقبله ومظاهر

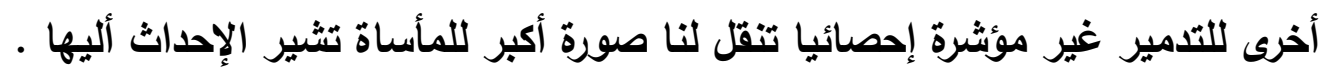

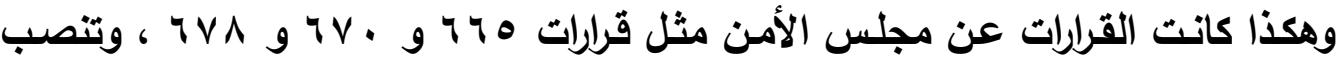

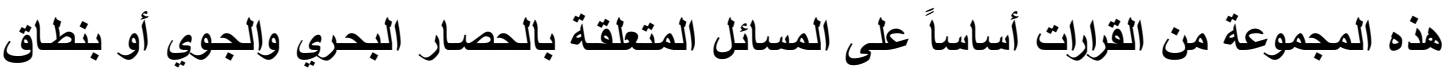

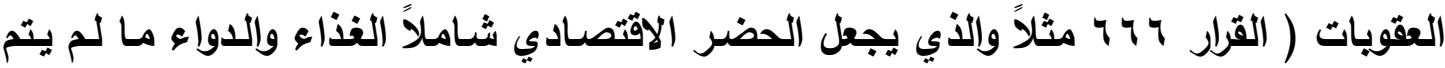
توزيعها بمعرفة الأمم المتحدة والصليب الأحمر ويها تم عزل العلق وحصاره وتحقيق إحدى الأهداف بتدميره وتغير موازين القوى في المنطقة. الى هذا اليوم لم تسجل بدقة مجريات الحياة اليومية وحوادثها في العراق أثناء الحصار

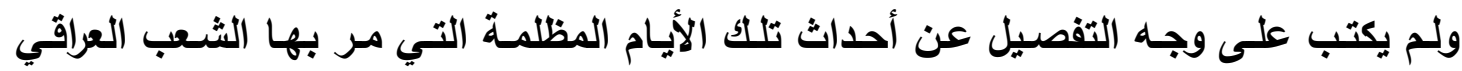

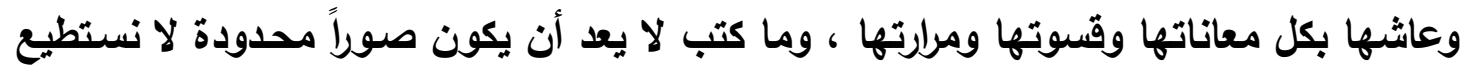

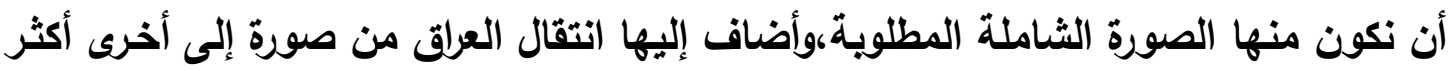

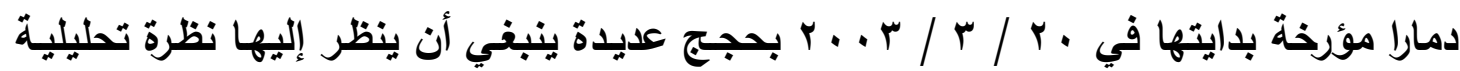

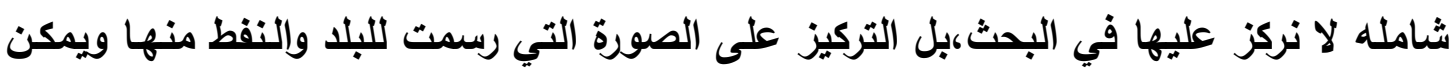

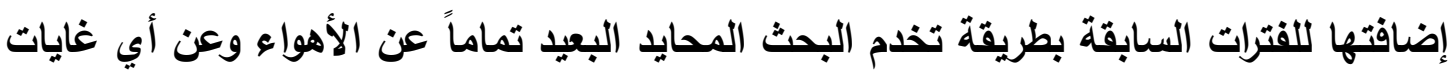
أخرى،أراجع نفسي والقارئ فيها في مختصر بسيط جـاً وكما يأتي :(1) محمد علي زيني ، الاقتصاد العراقي الواقع الحالي وتحديات المستقبل ، أبو ظبي ، مركز الإمارات

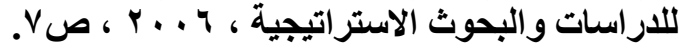

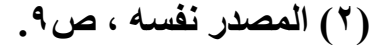

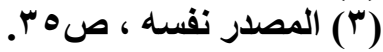


خامساً : تقدير دالة الإحداث : نظرة شاملة .

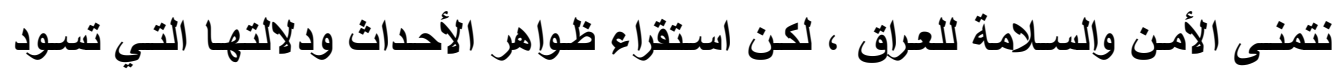

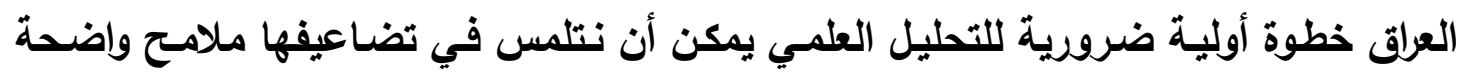
بصيغها المختلفة مثل : - مهمـا يقال عن فترة الاحتلال العسكري الأمريكي للعرلق والانسحاب وعدد القوات وطبيعة

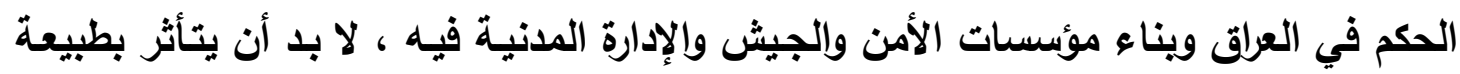

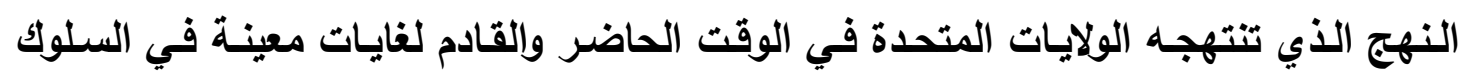
- الأمريكي - ريما تحاول الولايات المتحدة الأمريكية إقناع الثعب العراقي بأن نواياها حميدة فيما يتعلق بالنفط العراقي و أن ثروة النفط سوف تستخدم لفائدة الثعب العراقي مثل قرار مجلس الأمن

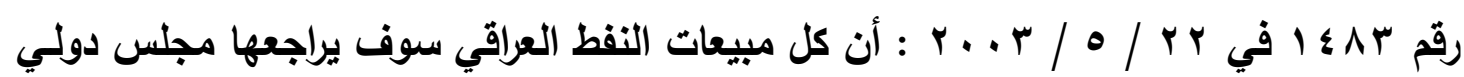

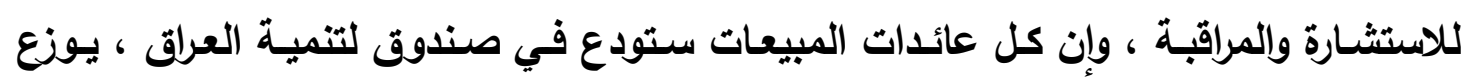

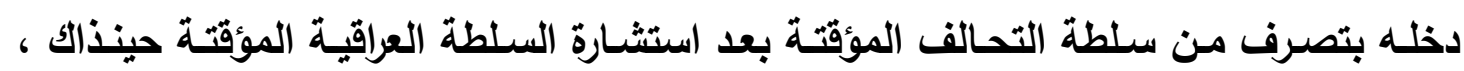

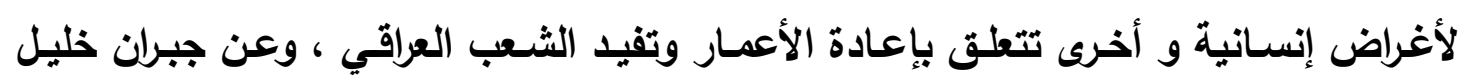
جبران نقول : ( ويل لأمةٍة تحسبُ المستُبدً بطلاً

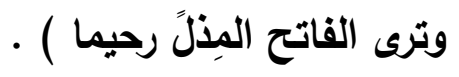
وهناك الكثير من الآراء والاجتهادات للريط بين الاحتلال والنفط مثل قول العئ السير اندرو

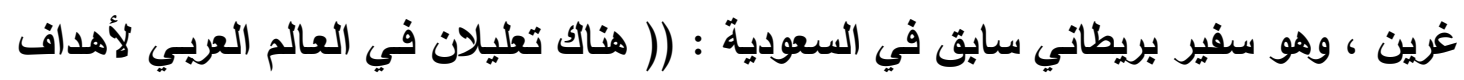

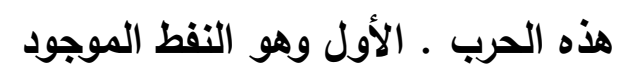

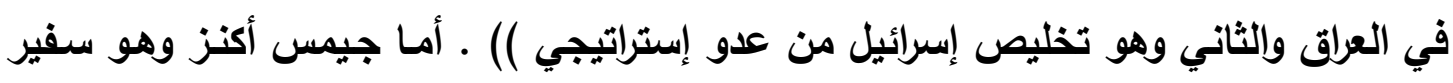

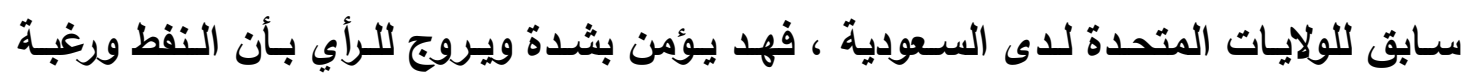

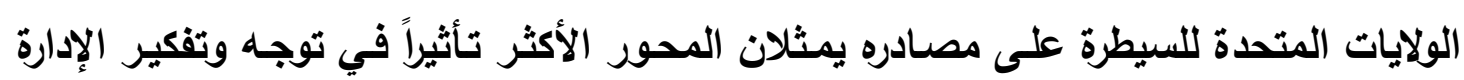

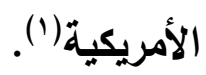
الرأي الثاني متصل بالأول ، بل يوجد غيرها الكثير ، وهذا أمر تثهل له السنوات، وما

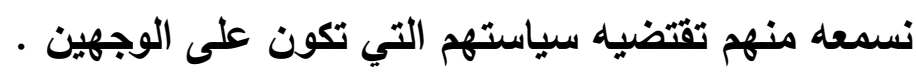


العرلق قد لا يشارك في صنع القرار الخاص بعائدات النفط واستخذاماتها من خلال مـا

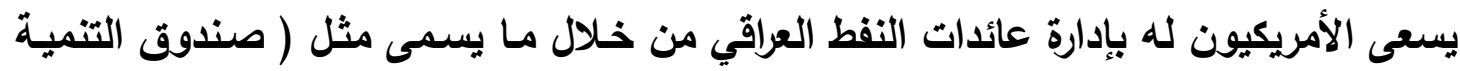
العراقية ) وما يمثله بمفاهيم أخرى لأهدافهم ، فكيف ستكون للبلد استقلالية اقتصادية في رسم

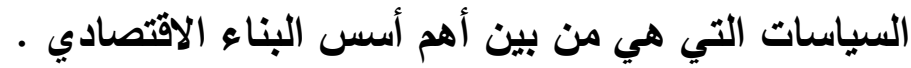

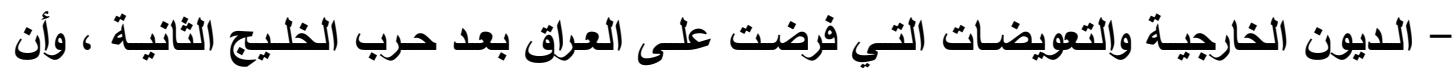

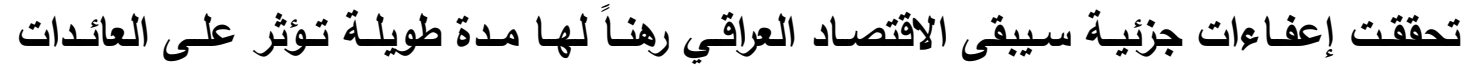
النفطية ويالتالي إعادة أعماره وتنميته . - تعد مسألة اجتذاب الاستثمارات الأجنبية إلى العرلق ولا سيما إذا ما ارتباتهت .

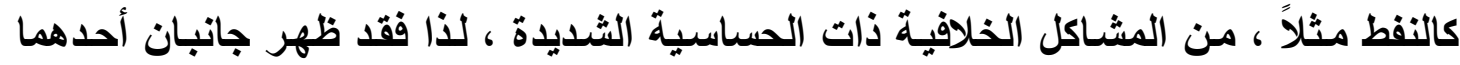

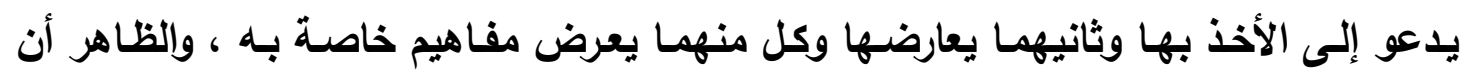
العرلق يسير مع جذب الاستثمارات الأجنبية ، وهذا متغير لله إبعاده السلبية على هذه الثروة

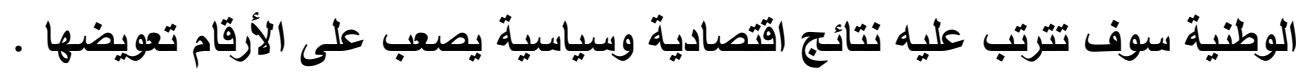

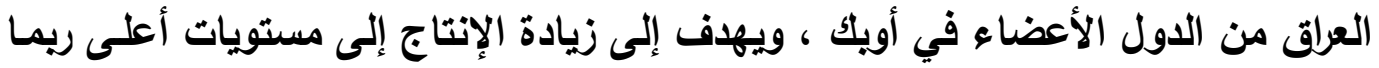

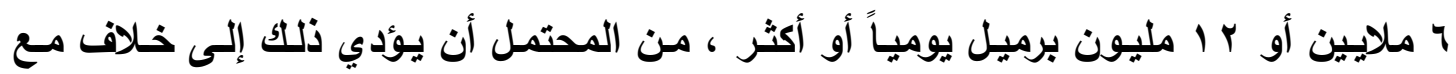

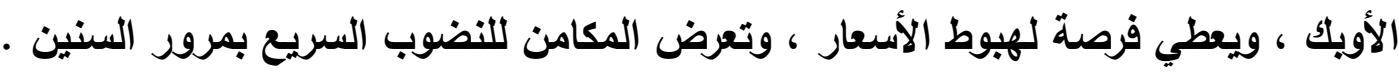

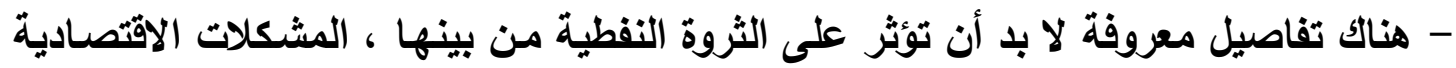

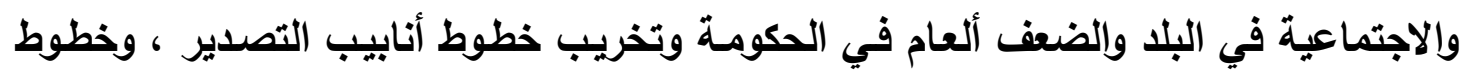
أنابيب النفط الخام التي تنذي مصافي التكرير المحلية ، والتهريب المستمر للمنتجات النفطية ، والوضع الأمني المتردي والخطف واخذ الرهائن والانقطاع المتكرر للتيار الكهربائي ، وغيرها

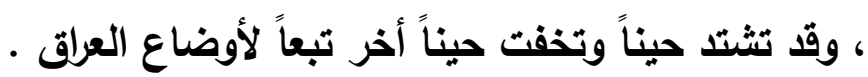

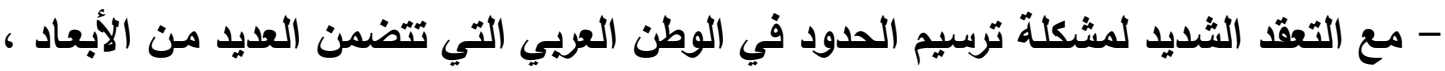

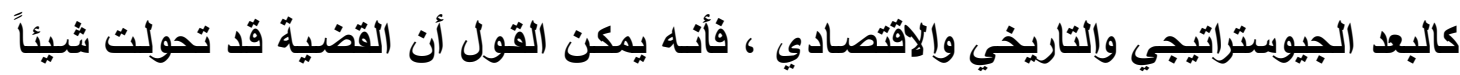

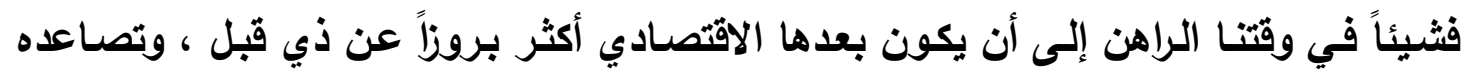

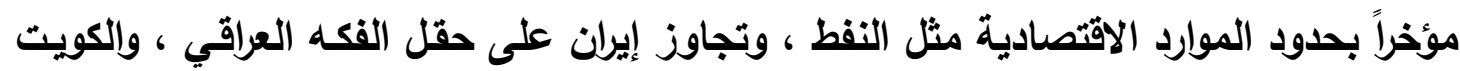

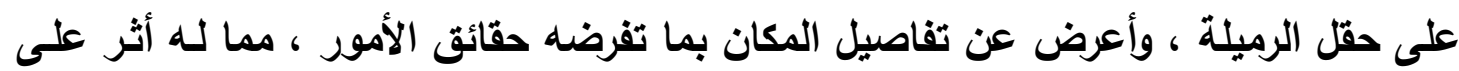
نصيب العراق فيها . - لن ندخل إلى أصل ومضمون الفيدرالية ونظام الحكم وتطور أحداث القضية الكرديـة في العلق ، لكن أثبير إلى حقيقة بسيطة وواضحة ومعروفة الآن بكردستان العرلق ،فهي منطقة

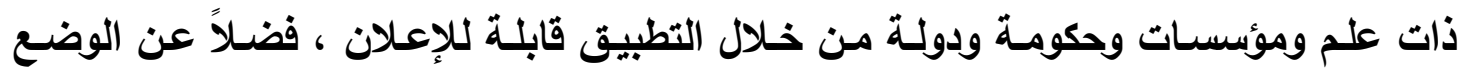


المستقبلي لكركوك الغنية بالنفط ، وهي على العموم تثمل مكامن نفطية عديدة من خصائص المكان ، التحكم بجزء كبير من نفط العراق . ويعد هذا وغيره لا بـ أن نتأمل واقع النفط العراقي ونتائج هذه الفترة المظلمـة في

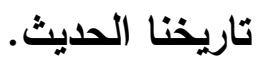

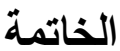

بالتأكيا ثمة وجهات نظر أخرى لنفط العرلق متباينة مع مؤثرات وإحصاءات هذا البحث

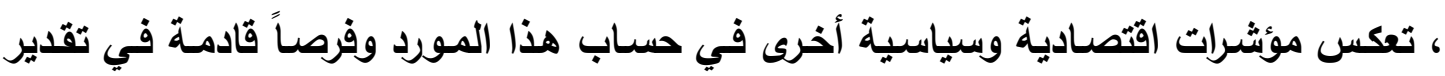

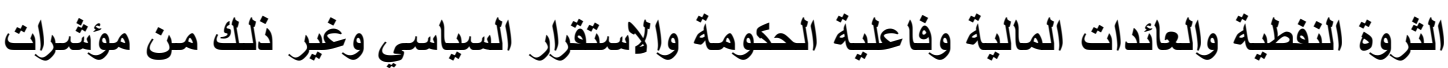
يتم توصيفها بحسب الفرضية المقابلة لهذا البحث . 
بهذه التقايرات نصل إلى صيغتين متخالفتين ، تكشف السنوات عن إحداهما في قياس الثروة ويأثر ظاهري وإجابة أسئلة رئيسة وأساسية منها : أين تكمن ثروة العرلق النفطية ؟ ومع ذلك المؤشرات المرتبطة بهذا التتبع العلمي محتوى ودلالة ، تفصح عن واقع لا يمكن

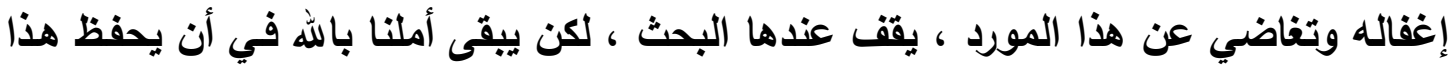

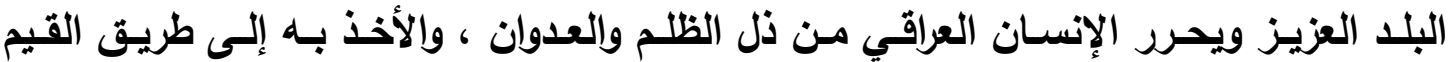

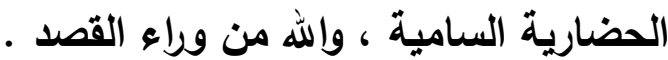

المصادر

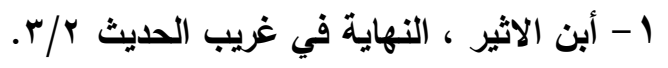

r- باقر ، طه ، مقدمة في تأريخ الحضارات القديمة ، الجزء الاول ، بغاد ، داب العار الثؤون الثثافية العامة ، .1914

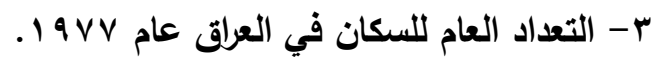

ع - الجميل ، سيار ، الموقع الجغرافي للعرلق واهميته الإستراتيجية ، في كتاب العراق دراسات في لسياسة العابة

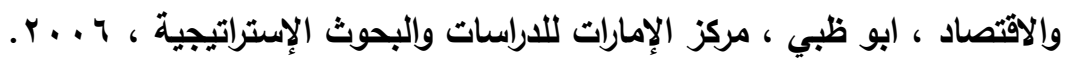


ه- حسين ، علي ، مستقبل تمويل الصناعة النفطية العراقية ، ابو ظبي ، مركز الامارات للاراسات والبحوث

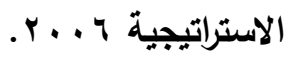

צ- حمادي ، سعدون ، مذكرات وآراء في شؤون النفط ، بيروت ، دار الطليعة ، ، ـ191 1.

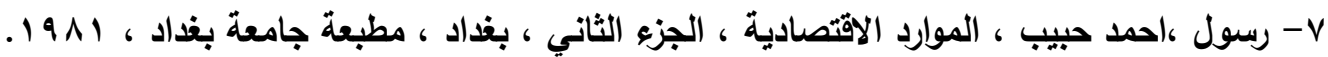

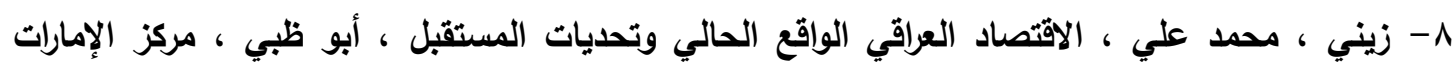

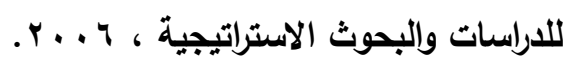

9- سلمان ، رمزي ، في كتاب : احتلال العرلق وتداعياته عربياً وإقليمياً ودولياً ، بيروت ، مركز دراسات

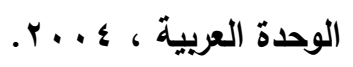

• 1 - سوسه ، أحمد ، حضارة وادي الرافدين بين الساميين والسومريين ، بغداد ، دار الرشيد للنشر لورة $.191 \cdot 6$

1 - البد الوهاب ، عبد المنعم واخرون ، جغرافية النفط والطاقة ، الموصل ، دار الكتب للطباعة والنشر ، .1911

r ا - عبد الجبار ، هشام وخلدون صبحي البصام ، التقرير التوضيحي لخارطة العرلق الجيولوجية الاقتصادية

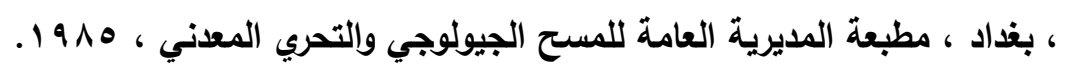

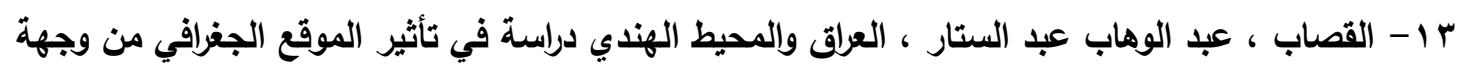

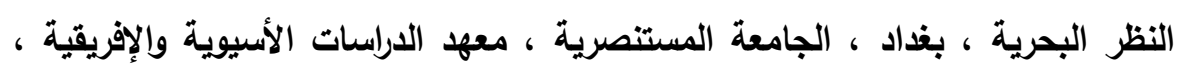

.1914

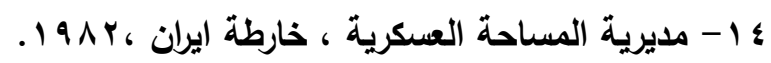

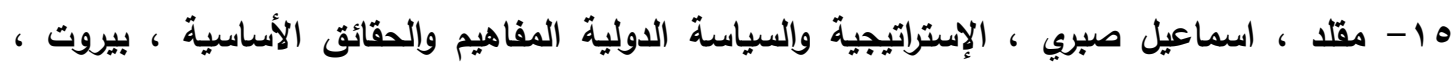

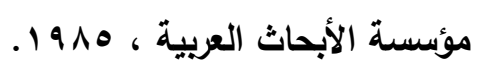

1 - 1 ناصر ، محمد رضا وصديقه باقر عبد ، حجم التبادل التجاري بين العرلق واقطار العالم حسب الفئات

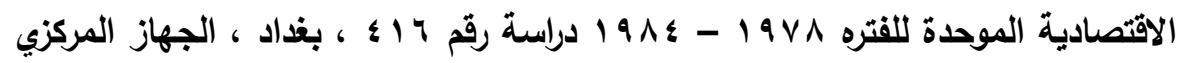

$$
\text { للأحصاء 19^v }
$$

V V ا النصيبي ، أبي القاسم بن حوقل ، صورة الارض ، بيروت ، مكتبة الحياة ، سنة.

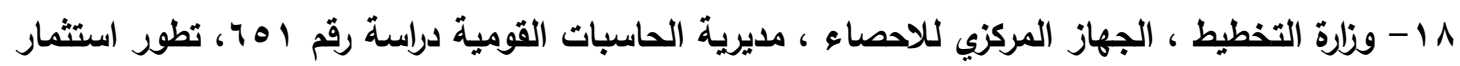

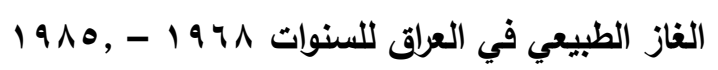

Secretariat OPEC Annual statistical Bulletin , 1992 , The Organization of The Petroleum Exporting Countries , Vienna , 1993 